\title{
Analysis of Alkaline Foam to Water Temperature Model
}

\author{
Zhen Xu1 ${ }^{*}$, Lihong Zhao"\#, Kai Tan ${ }^{3}$ \\ ${ }^{1}$ Institution of Mechanical Engineering, University of the South of China, Hengyang, China \\ ${ }^{2}$ Institution of Nuclear Six, University of the South of China, Hengyang, China \\ ${ }^{3}$ Institution of Nuclear Science and Technology, University of the South of China, Hengyang, China \\ Email: 1170268911@qq.com
}

Received 3 May 2016; accepted 9 August 2016; published 12 August 2016

Copyright (C) 2016 by authors and Scientific Research Publishing Inc.

This work is licensed under the Creative Commons Attribution International License (CC BY).

http://creativecommons.org/licenses/by/4.0/

c) (i) Open Access

\begin{abstract}
Factors affecting bath water temperature model include the shape and size of a bath, people's gesture, volume, individual temperature adaptation as well as body movement in the bath. In addition, the bathroom space, ambient temperature and bath materials will also affect changes of the water temperature to a certain extent. In this paper, the cooling function and linear regression method are used and the MATLAB software is also used to simulate the model of water temperature, alkaline bath foams that obtained can accelerate changes in water temperature.
\end{abstract}

\section{Keywords}

Water Temperature Model, Cooling Function, Linear Regression Analysis

\section{Introduction}

In this article, the tap water injection of the liquid flow rate, flow velocity obtained is the speed of the water and can make the water temperature keep the minimum flow rate balance. Balance, each point temperature in cylinder meet, therefore only needs in the convection heat transfer equation of the model and the conditions can be obtained by temperature reach stable each point of the temperature distribution in cylinder. Bath tub, not with auxiliary heating system insulation, but it is just a simple tank. When a person is in the bath, in order to maintain the temperature of the bath and to make people feel a degree of comfort, faucet will continue to increase a certain amount of hot water bath and then heat to maintain the temperature of the bath. When the water bath reaches its capacity, the excess water will overflow through the gutter.

"Zhen Xu (1989-), male, a master graduate student. Major: Electromechanical testing and control.

${ }^{\#}$ Lihong Zhao (1967-), male, professor, a tutor of master graduate students. Major: Electromechanical testing and control, medical device testing. 


\section{The Influence of Detergent on the Model}

In this subject, when volume of bath crock is certain, its shape and posture and body movement of man will have an effect on the temperature of bath crock model in certain degree, which has a great influence on the water temperature model of the human body movement for the design. Define the cooling function [1]:

$$
f(x)=a(x+b)^{2}
$$

$a$ — the opening arc coefficient, $x$ — the bath side arc width, $f(x)$ — the bath side arc height, $b$-parameter.

From Table 1, due to the different factors to the water temperature model, in order to simple the model reflection, using linear regression analysis method [2] to analyse.

From Table 2, we can see the average height of the top three countries in the world [3]. They are Holland, Denmark, and Norway, the male average height of each country is $183.8 \mathrm{~cm}, 182.6 \mathrm{~cm}$ and $182.4 \mathrm{~cm}$. Therefore, taking a man's height that is $185 \mathrm{~cm}$, by the equation, we can get the man's shoulder width and back breadth, back length, respectively, these are $47 \mathrm{~cm}, 43.5 \mathrm{~cm} 36 \mathrm{~cm}$.

When $b=0$,consider establishing the cylinder wall surface equation: $y=a x^{2}$, The bathtub is a parabolic, due to the known his height is $185 \mathrm{~cm}$ covers the average height of most countries in the world, so I can take this one back long as the height of the bath, Because the man's shoulder breadth also know, so to determine the surface $y$ $=a x^{2}$ coefficient of a value, considering the bathtub openings at least just match with the man's shoulder width, it can be concluded:

$$
l=a *(0.5 * W)^{2}, a=l /(0.5 * W)^{2}
$$

$L$ and $W$ in (2) type, get $a=0.079$, namely, the cylinder wall surface equation: $y=0.079 * x^{2}, 0<z<L-l$ $=141.5$. Add detergent temperature field of cylinder in the inland waters mainly has two aspects: the influence of the first, detergent foam. Foam floating on the surface of the water, which is equivalent to add a protective layer on the surface of the water. Second, add detergent will change of water quality acid and alkali. The first effect is conductive to the stability of the internal temperature field in cylinder [4], and the second case, access to information, general cleaning agent is basic for alkaline substances, after adding detergent, it has the greatest influence on water quality to the acid and alkaline water, the greater, the PH conductivity factor, this leads to the border cooling effect on the waters of the temperature field in cylinder. By using the second case, a proper increase will affect the function of parameters, the concrete numerical value can be achieved by experimental data fitting. Using an appropriate value of MATLAB software to calculate the numerical solution, and draw the image with no detergent temperature field image comparison [5].

\section{Table 1. Linear element regression of each position and height.}

\begin{tabular}{lccccc}
\hline \multirow{2}{*}{ Correlation coefficient } & \multicolumn{2}{c}{ Unitary regression value } & The regression equation & Simplified expression \\
\cline { 3 - 6 } & & $\mathrm{M}$ & $\mathrm{B}$ & \multicolumn{2}{c}{$\mathrm{Y}=\mathrm{MX}+\mathrm{B}$} \\
\hline Full shoulder & 0.935228 & 0.176737 & 9.60326 & $\mathrm{Y}=0.18 \mathrm{X}+9.6$. & $\mathrm{Y}=0.2 \mathrm{X}+10$ \\
Back length & 0.997725 & 0.290118 & -11.5919 & $\mathrm{Y}=0.3 \mathrm{X}-11.6$ & $\mathrm{Y}=0.3 \mathrm{X}-12$ \\
Back width & 0.980125 & 0.203581 & 1.031154 & $\mathrm{Y}=0.2 \mathrm{X}-1$ & $\mathrm{Y}=0.2 \mathrm{X}-1$ \\
\hline
\end{tabular}

Table 2. The average height of four countries.

\begin{tabular}{lcc}
\hline Country & Ranking & Male average height \\
Holland & 1 & 2 \\
Denmark & 2 & $183.8 \mathrm{~cm}$ \\
Norway & 3 & $182.6 \mathrm{~cm}$ \\
U.S.A & 19 & $182.4 \mathrm{~cm}$ \\
China & 57 & $171.7 \mathrm{~cm}$
\end{tabular}


Not add a bubble bath, Thermal diffusion coefficient equals 0.06 after 1 hour(s), Cross section temperature field distribution of $3 \mathrm{~d}$ figure

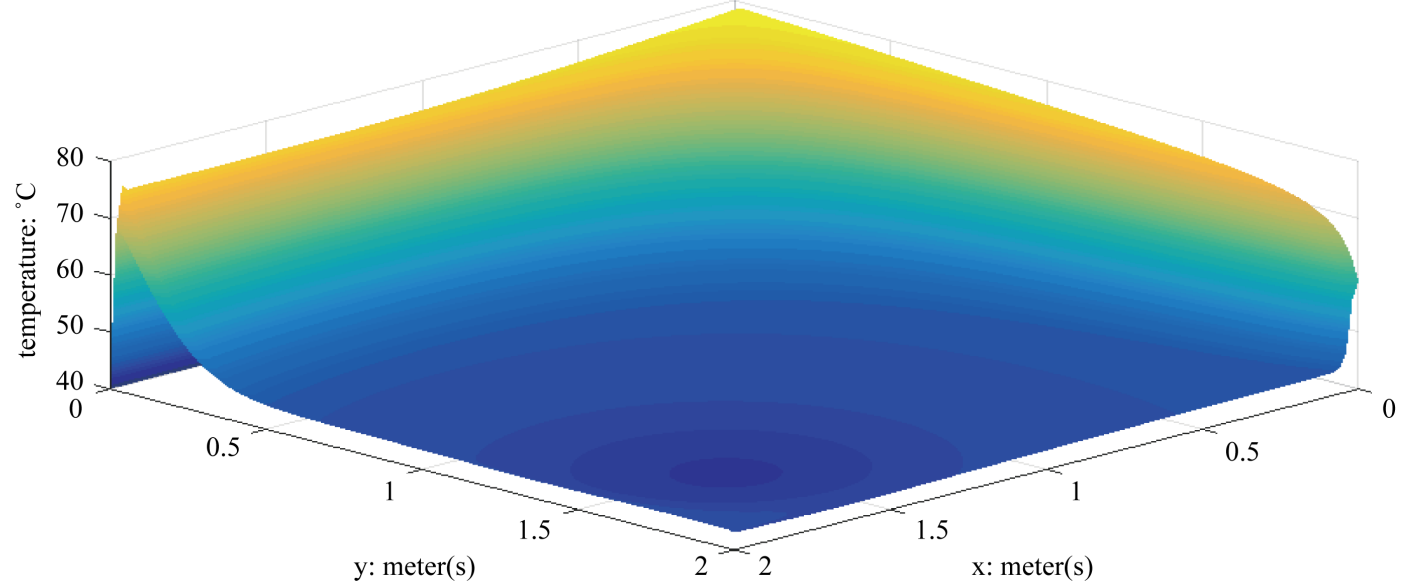

Figure 1. Not add a bubble, $\operatorname{Pr}=0.06$, get $\mathrm{T}=1$ (hour) moment in the cross section temperature field distribution of $3 \mathrm{~d}$ diagram.

Add a bubble bath, Thermal diffusion coefficient equals 0.06 after 1 hour(s), Cross section temperature field distribution of $3 \mathrm{~d}$ figure

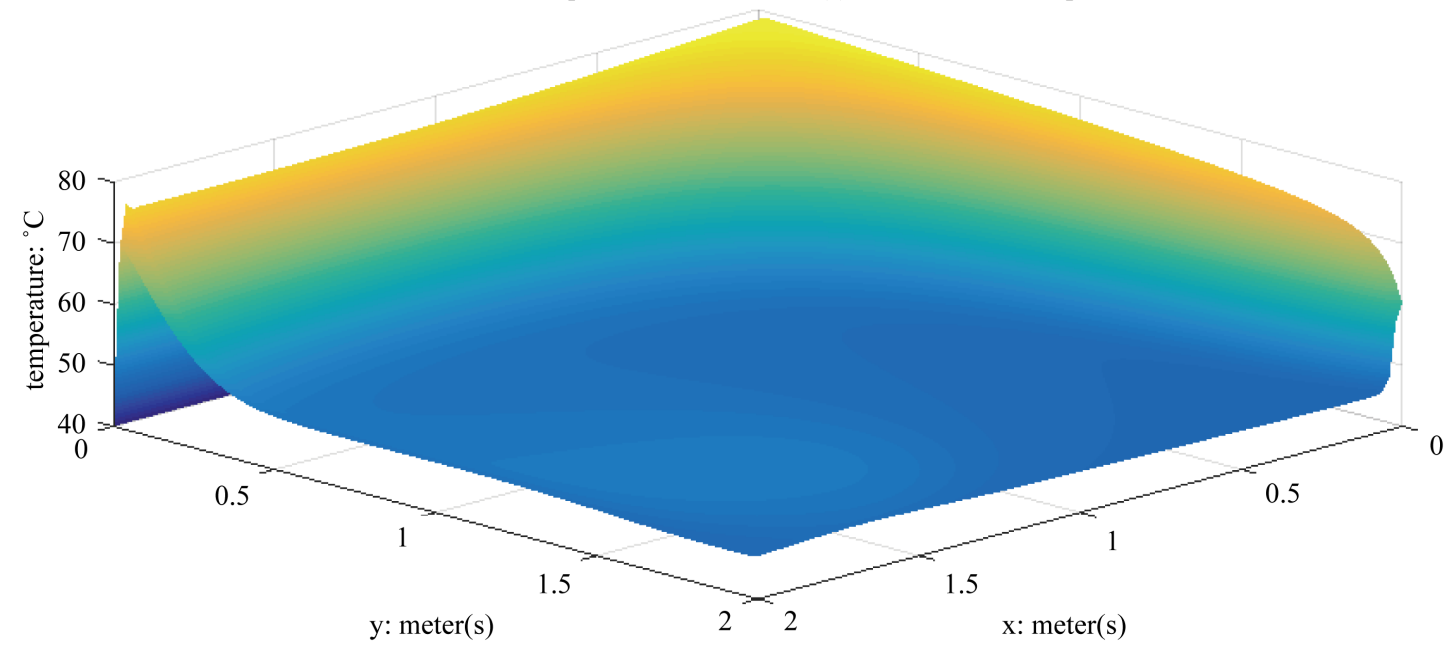

Figure 2. Add a bubble, $\operatorname{Pr}=0.06$, get $\mathrm{T}=1$ (hour) moment in the cross section temperature field distribution of $3 \mathrm{~d}$ diagram.

\section{Simulation Results}

Through the analysis and comparison of Figure 1 and Figure 2, we can find it is apparent that not adding detergent air near the surface of the air makes temperature fall slowly while adding detergent air near the air surface makes temperature drop quickly.

\section{Conclusions}

Considering the temperature distribution model of cuboid bath, we adopt the parallel section method because of the symmetry of the cuboid. The bath water temperature distribution field is obtained under the influence of different shapes and individual factors by establishing the mathematical model. Although the cylinder wall heat loss of it is very few, most of these calories from contact with the cylinder wall of water lost out, just to lower the temperature of the cylinder wall near the water, which makes us get the result of the cylinder wall near do not tally with the actual situation.

Not adding detergent air near the surface of the air makes temperature fall slowly while adding detergent air near the air surface makes temperature drop quickly. 


\section{References}

[1] Qiao, H.T., Zhang, Y.C. and Liu, S.T. (2011) Discuss of Thermal Structure Topology Optimization Objective Function. China Mechanical Engineering, 5.

[2] Zhao, J. and Li, Z.H. (2008) The Establishment of Pattern Prototype for 12 to 17-Year-Old Male Teenagers.

[3] (2016) The Average Height of Men and Women around the World. Baidu Library.

[4] Xia, M. (2003) Fluid-Africa Center Symmetry Point Source Attenuation of Shock Wavefront Testing and Propagation Characteristics. Nanjing University of Science and Technology, Nanjing.

[5] (2014) MATLAB Solution of Differential Partial Equations. Baidu Library.

\section{Submit or recommend next manuscript to SCIRP and we will provide best service for you:}

Accepting pre-submission inquiries through Email, Facebook, Linkedin, Twitter, etc A wide selection of journals (inclusive of 9 subjects, more than 200 journals)

Providing a 24-hour high-quality service

User-friendly online submission system

Fair and swift peer-review system

Efficient typesetting and proofreading procedure

Display of the result of downloads and visits, as well as the number of cited articles

Maximum dissemination of your research work

Submit your manuscript at: http://papersubmission.scirp.org/ 